\title{
Organic Solvents Transport Through Alkali-Treated Agro-waste Microfibre Incorporated with Low Density Polyethylene Composites
}

\author{
Henry Chinedu Obasi ${ }^{1,4,}$, , Simeon Nwanonenyi ${ }^{1}$, Innocent Eze ${ }^{1}$, Ihuoma Chukwujike ${ }^{2}$, \\ Chioma Anyiam ${ }^{1}$, Felix Aguele ${ }^{3}$, Kashif Ijaz ${ }^{4}$ \\ ${ }^{1}$ Department of Polymer and Textile Engineering, Federal University of Technology, Owerri, Nigeria \\ ${ }^{2}$ Department of Polymer and Textile Engineering, Nnamdi Azikiwe University, Awka, Nigeria \\ ${ }^{3}$ Department of Chemical Engineering, Michael Okpara University of Agriculture, Umudike, Nigeria \\ ${ }^{4}$ Interdisciplinary Research Centre in Biomedical Materials, COMSATS Institute of Information Technology, Lahore, Pakistan
}

\author{
Email address: \\ neduobasi23@gmail.com (H. C. Obasi) \\ ${ }^{*}$ Corresponding author
}

\section{To cite this article:}

Henry Chinedu Obasi, Simeon Nwanonenyi, Innocent Eze, Ihuoma Chukwujike, Chioma Anyiam, Felix Aguele, Kashif Ijaz. Organic Solvents Transport Through Alkali-Treated Agro-waste Microfibre Incorporated with Low Density Polyethylene Composites. American Journal of Polymer Science and Technology. Vol. 3, No. 4, 2017, pp. 50-63. doi: 10.11648/j.ajpst.20170304.11

Received: May 8, 2017; Accepted: May 31, 2017; Published: June 30, 2017

\begin{abstract}
We report the transport behaviour of low density polyethylene composites containing both untreated and alkalitreated agro-waste microfibre in three aromatic organic solvents (benzene, toluene, and xylene) at 40,60 and $80^{\circ} \mathrm{C}$ by the conventional weight-gain method. The effects of fibre content, alkali treatment, and filler particle size on solvent sorption were analysed. Transport parameters such as diffusion coefficient, sorption coefficient, and permeation coefficient have been calculated in terms of microfibre content, particle size, nature of the solvent, and temperature. It was observed that all the systems follow the Fickian mode of transport on increasing temperature. The van't Hoff's relationship was used to determine the thermodynamic parameters and was found that the estimated free energies of sorption were all positive, indicating nonspontaneity of the solubility of micro fibre/LDPE composites. The first order kinetic rate constant and swelling parameters were also evaluated.
\end{abstract}

Keywords: Agro-waste Fibre, Alkali Treatment, Transport Parameter, Fickian, Activation Energies

\section{Introduction}

The performance of polymeric composites in a solvent and solvent mixed media can be threatened due to swelling of the composite matrix. The understanding of the performance of polymers in the environment of hazardous solvents, vapours and temperature is, therefore, essential for successful applications as structural engineering materials. Solvent sorption and diffusion are the limiting factors of polymer end-use applications because these processes might utter the mechanical properties and sometimes lead to failure in polymer structures [1]. Transport behaviour of solvents differs from one polymeric system to another due to differences in structural morphologies. Rubbery polymers are unsaturated with segmental mobility and free volume between molecules giving rise to smooth and easy diffusion of molecules through them whereas diffusion in dense structured glassy polymers with very little voids is more complex. For filled polymers whether heterogeneous or homogeneous, diffusion depends on its composition, miscibility, phase morphology, and nature of fillers. In homogeneous blends, the diffusion process is influenced by the interaction between the components [2-5] while for heterogeneous blends, the interfacial phenomena and the rubbery or glassy nature of the phases are important [6].

The diffusion of solvents through polymeric films, filled blends, membranes and composites have been investigated by several researchers [7-13]. Cates and White [14-16] were among the pioneer researchers to study the diffusion of solvents through polymeric membranes. They investigated 
the sorption behaviour of water in blends of polyacrylonitrile and cellulose acetate, cellulose and silk respectively. On their part, Jacob et al [17] studied the influence of temperature on the diffusion of water molecules through sisal and oil palm fibre filled natural rubber polymer composites. They found that the mechanism of diffusion in the neat rubber sample is Fickian in nature, while the filled composites showed nonFickian behaviour. Sorption behaviour of isora/natural rubber composites has been investigated by Lovely et al. [18]. Their findings revealed that the uptake of aromatic solvents is higher than aliphatic solvents for the composites. Mathew and Kuriakose on their own reported that the mechanism of transport is Fickian in the study of the diffusion of organic solvents through lignin filled NR composites [19]. The swelling behaviour in compressed butyl rubber reinforced with carbon black was investigated by Gasson et al [20]. The swelling of the samples in both benzene and kerosene was measured and found to be dependent on both filler content and the type of solvent used. Also, Kwei and Kunins [21] observed that the sorption of chloroform by an epoxy resin was lowered by about $70 \%$ when $5 \%$ filler was incorporated. Furthermore, George, et al. [22] investigated the effect of different types of fillers such as cork, silica and carbon black on the transport of aromatic solvents in isotactic polypropylene/acrylonitrile-co-butadiene rubber blends.

Agriculture is one the mainstay of countries in tropical regions. Nigeria as a tropical country is endowed with agricultural resources like palm trees. A Large chunk of palm agro-waste fibres is disposed of as wastes yearly from various oil mills and homes due to lack of use for these materials. The current research in the field of palm agro-waste fibres focuses on utilising fibres from palm fruits for use in nonwoven materials. Efforts to find utilisation of these materials have resulted mostly in low value or limited applications. In this regard, palm agro-waste fibre seems to be an interesting candidate because of its chemical composition. The motivation for such a search is based on ecological reasons. Hence, the use of the waste fibre as an alternative to commercial fillers is of great interest. In the recent years, palm agro-waste (mesocarp) fibres have been used as natural fillers to develop thermoplastic-based composites.

Low-density polyethylene (LDPE) is a semi-crystalline solid with a reasonable degree of crystallinity in the $50-60 \%$ range that leads to several properties such as opacity, tensile strength, tear strength, rigidity and chemical resistance, flexibility even at a low temperature $[23,24]$. LDPE is one of the most commonly used thermoplastics to develop composites reinforced by different natural materials, cellulose [25], lignin [26], starch [27]. Therefore, blending the fibres with thermoplastic polymers such as LDPE could be a novel way of turning waste into wealth.

The aim of the present work is to study the transport properties of aromatic solvents (benzene, toluene and xylene) through agro-waste microfibre incorporated with low density polyethylene at 40,60 and $80^{\circ} \mathrm{C}$ temperature. To our knowledge, no work has been done on the transport of these organic solvents through agro-waste (oil palm pressed) fibre incorporated with low density polyethylene composites. The effect of the penetrant molecule, filler content, filler treatment and particle size were studied. From the sorption data, matrixsolvent interaction parameter, mechanism of swelling, thermodynamic parameters like entropy, enthalpy, Gibbs free energy and first order kinetics of swelling were evaluated.

\section{Experimental}

The agro-waste microfiber (MF) filled low density polyethylene (LDPE) composites used in this study were fabricated at CeePlast Industries, Aba, Nigeria. The agrowaste fibre was obtained from Ada Palm Oil Mills, Ohaji, Owerri, Nigeria. Wet extraction method that used hot water as described elsewhere, [28] was employed to leach out the remaining residual oil from the agro-waste fibre which was retained after processing and later dried. A portion of the fibre was then treated with $5 \% \mathrm{NaOH}$ solution, washed severally to neutrality and dried. Both alkali treated micro fibre $(\mathrm{A} \mu \mathrm{F})$ and untreated micro fibre $(\mu \mathrm{F})$ were processed and sieved to $425 \mu \mathrm{m}, 500 \mu \mathrm{m}$ and $600 \mu \mathrm{m}$ mesh sizes. The following weight percent fraction of micro fibre was used in compounding the composites: 10, 20 and 30 wt. \%. The obtained fabricated sheets were vacuum dried overnight and stored in an airtight container for further use. The solvents used in this study were analytical grade benzene, toluene, and xylene and were used without further purifications. The properties of the solvents used are presented in Table 1. The procedure for the sorption experiment was as described previously [29] save that in this study, the following temperatures were investigated: 40,60 , and $80^{\circ} \mathrm{C}$.

Table 1. Properties of solvents used.

\begin{tabular}{llll}
\hline Solvent & Density, $\left(\mathbf{g c m}^{-3}\right)$ & $\begin{array}{l}\text { Mol. Mass } \\
\text { Volume, }\left(\mathbf{g m o l}^{\mathbf{1}}\right)\end{array}$ & $\begin{array}{l}\text { Solubility } \\
\text { Parameter, }(\mathbf{M p a})^{\mathbf{1 / 2}}\end{array}$ \\
\hline Benzene & 0.876 & 78.12 & 18.7 \\
Toluene & 0.867 & 92.14 & 18.3 \\
Xylene & 0.865 & 106.17 & 18.2 \\
\hline
\end{tabular}

\section{Results and Discussion}

\subsection{Analysis of Swelling Data}

\subsubsection{Determination of $Q_{t}$ (Mol \% Uptake of the Solvent)}

The sorption data of different solvents into agro-waste microfibre (MF)/low density polyethylene (LDPE) composites at different blend composition and filler content has been determined. The sorption behaviour of the MF/LDPE composites prepared in three different particle sizes of agro-waste microfibre, namely, 425, 500 and 600 $\mu \mathrm{m}$, were studied at the following temperatures, 40,60 , and $80^{\circ} \mathrm{C}$. It is expressed as the molar percentage uptake $\left(\% \mathrm{Q}_{\mathrm{t}}\right)$ of solvent per gramme of MF/LDPE composites and was calculated using equation 1 . The $\mathrm{Q}_{t}$ values got have been plotted as a function of square root of time, to design the sorption curves. 


$$
\mathrm{Q}_{\mathrm{t}} \mathrm{mol}(\%)=\frac{\text { Mass of sorbed at a given time/Molecular mass of the solvent }}{\text { Initial mass of the polymer sample }} \times 100
$$

\subsubsection{Effect of Filler Content on $Q_{t}$}

The effect of filler content on the mole percent uptake by the MF/LDPE composites taking at $40^{\circ} \mathrm{C}$ for $425 \mu \mathrm{m}$ for the three solvents (benzene, toluene and xylene) was plotted against the square root of time $(\sqrt{t})$ as shown in Figures $1-3$. Other composite systems showed similar behaviour. Each of these figures indicates that there is an initial increase in mass of the solvent sorbed by the composites and at maximum absorption the mass of solvent sorbed remains constant with time showing attainment of equilibrium plateau. Nature of the fillers, compatibility and the degree of adhesion with the polymer matrix are the main factors which significantly affect the solvent uptake in LDPE filled composites. At the early stages of sorption, composites undergo rapid cavitation exposing greater surface areas which increase the percolation of the solvent leading to higher solvent diffusion rate [30]. The figures show that addition of microfibre to LDPE lowers the mole percent of solvent uptake and the decrease is in the order of $30<20<10 \mathrm{wt}$. \%. It is reasonable to believe that the free volume decreases with increase in filler content thereby narrowing the pathways for solvent penetration. The decrease in the pathway is dependent on the volume fraction, shape and orientation of the filler. If the filler forms a poor mix with the polymer, voids tend to occur at the interface, which leads to an increase in free volume of the system and consequently, to an increase in sorption.

\subsubsection{Effect of Particle Sizes on $Q_{t}$}

The variation of solvent uptake by the MF/LDPE composites for toluene solvent at $40^{\circ} \mathrm{C}$ as a function of filler particle sizes is given in Figure 4. The percent mole uptake is found to decrease with a decrease in particle size in the order $600 \mu \mathrm{m}>500 \mu \mathrm{m}>400 \mu \mathrm{m}$. The behaviour is like all blend compositions and the other solvents studied but with reduced values for alkali treated composites. The dispersion of the particles differs with particle size when the content is the same and the average interparticle distance reduces with the decrease in particle size. The lowest micron size filler is predominantly finer with higher surface area and understandably improves filler/polymer interactions. Moreover, low viscous polyethylene provided better wetting of the smaller filler particles, which have larger surface area per unit volume, and thus more filler surface area is available for the matrix.

\subsubsection{Effect of Temperature on $Q_{t}$}

The effect of temperature in aromatic solvents was investigated at 40,60 , and $80^{\circ} \mathrm{C}$. For our explanation, here, the effect of temperature at $500 \mu \mathrm{m}$ for $10 \mathrm{wt} \%$ is shown and it represents the behaviour of other compositions of the composites is illustrated in Figure 5. In all cases, as the temperature increases, the rate of solvent uptake increases indicating that the rate of solvent ingress into the composites is temperature dependent. This can be attributed to the increase in free volume because of the increase in segmental motion of the polymer matrix as well as the gain in kinetic energy by the solvent molecules which resulted in an increased the number collisions at the matrix phase. Again, at a higher temperature, the viscosity of the solvent is reduced which in turn increases the rate of flow of solvent into the composites. The increase in the mass of solvent sorbed by polymers with temperature had been reported elsewhere in the literature [29, 31-33].

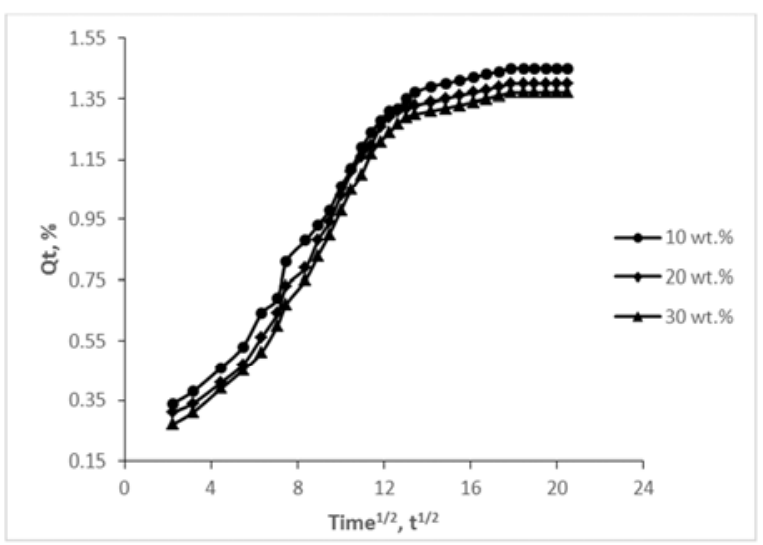

Figure 1. Effect of filler content on $Q_{t}$ of Microfibre/LDPE Composites at $40^{\circ} \mathrm{C}$ for $425 \mu \mathrm{m}$ in Benzene.

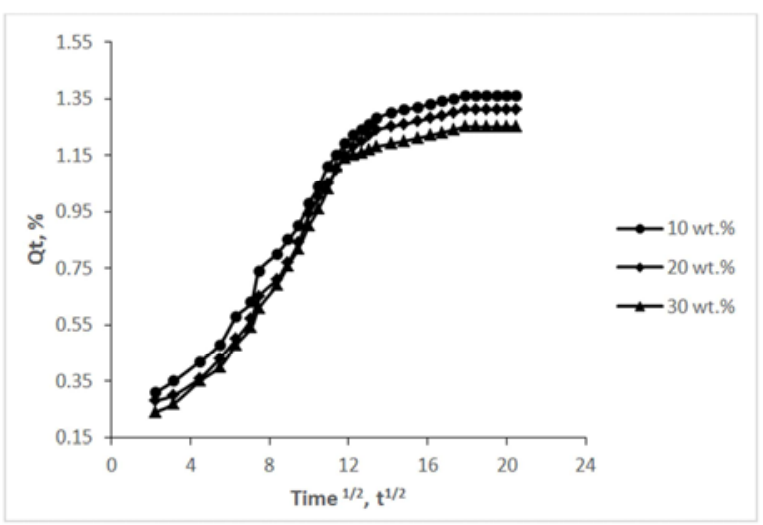

Figure 2. Effect of filler content on $Q_{t}$ of Microfibre/LDPE Composites at $40^{\circ} \mathrm{C}$ for $425 \mu \mathrm{m}$ in Toluene.

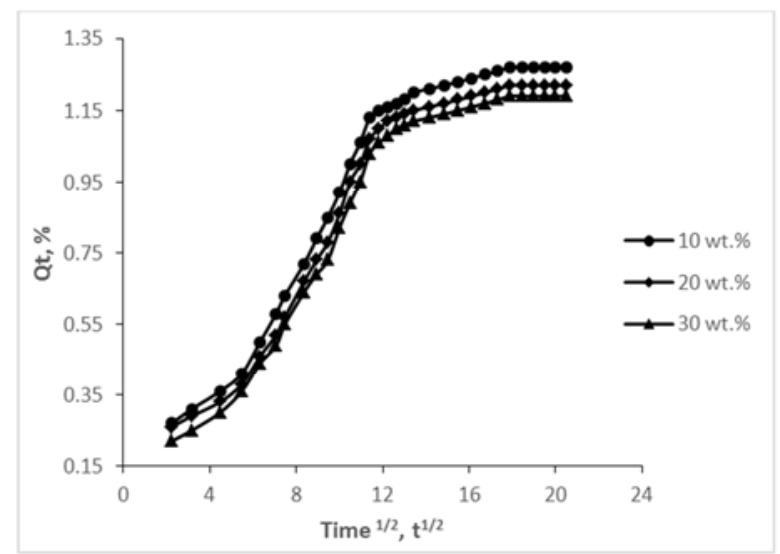

Figure 3. Effect of filler content on $Q_{t}$ of Microfibre/LDPE Composites at $40^{\circ} \mathrm{C}$ for $425 \mu \mathrm{m}$ in Xylene. 


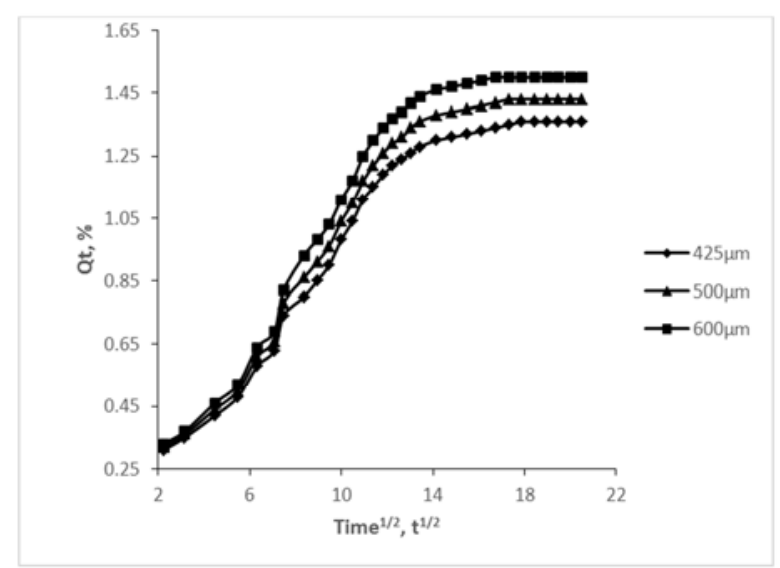

Figure 4. Effect of particle size on $Q_{t}$ of Microfibre/LDPE Composites at $40^{\circ} \mathrm{C}$ for $10 \mathrm{wt} . \%$ in Toluene.

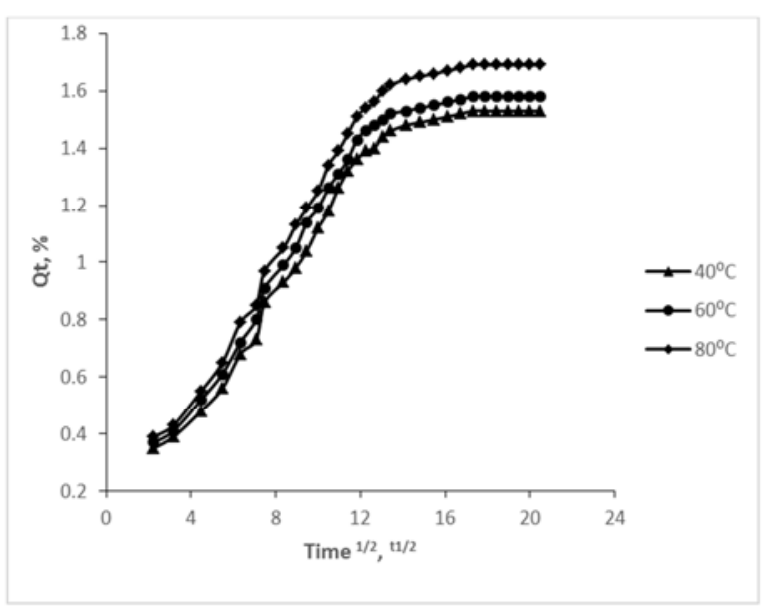

Figure 5. Effect of Temperature on $Q_{t}$ of Microfibre/LDPE composites at $500 \mu \mathrm{m}$ for $10 \mathrm{wt} . \%$.

\subsubsection{Effect of Alkali Treatment on $Q_{t}$}

The mole percent uptake of the solvents reveals that at any solvent for a given filler particle size used is higher for unmodified microfibre/LDPE composites compared with their treated counterparts as shown in Figure 6 for microfibre/LDPE composites at $60^{\circ} \mathrm{C}$ for $10 \mathrm{wt}$. $\%$ in xylene. This is obvious as alkali treatment helps to improve the interfacial incompatibility between the matrix and the filler thus reducing the solvent uptake. In the presence of a strong interface, fewer voids occur in the interfacial region and tighter packing within the fibre/matrix network are possible which make it hard for solvent molecules ingression. It has been reported that alkali treatment improves the fibre surface adhesive characteristics and topography by removing natural waxy materials, hemicellulose, and artificial impurities [34]. Furthermore, alkali treatment seems to be a medium for providing a chemical strength between filler and matrix [35].

\subsubsection{Effect of Penetrant Size on $Q_{t}$}

The mole percent uptake of solvents by microfibre/LDPE composites increases with increasing the penetrant size from benzene to xylene as presented in Figure 7. This observation can be explained based on the difference in solubility parameter between the polymer and penetrants. The difference in the solubility parameters between the polymer and the penetrant is often used to characterise the sorption behaviour of the penetrant in the polymer membrane [36, 37]. High solubility and penetration are obtained when the solubility parameter difference between the polymer and the penetrant is small. For the aromatic solvents used in this study, the uptake is in accordance with the solubility parameter difference, i.e., xylene $>$ toluene $>$ benzene as shown in Figure 7. Our results agree with the findings of some researchers that used the same type of aromatic solvents [31, 32, 38, 39]. Although several researchers have reported the increase in solvent uptake with decreasing penetrant size $[22,38,40,41]$. They linked this behaviour on the grounds of free volume theory in which the diffusion rate of solvents through polymers depends on the rate with which the polymer chain segments exchange their positions with solvents.

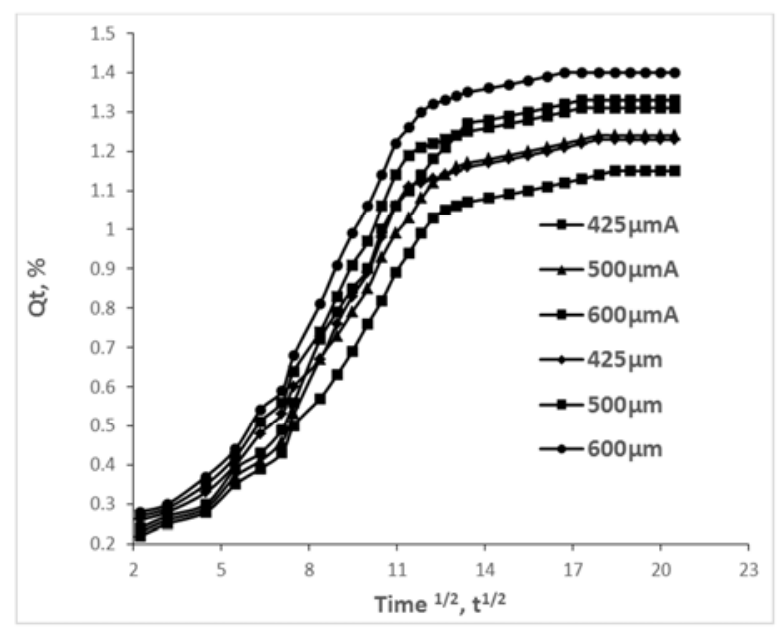

Figure 6. Effect of filler treatment on $Q_{t}$ of Microfibre/LDPE Composites at $60^{\circ} \mathrm{C}$ for $30 \mathrm{wt} . \%$ in Xylene.

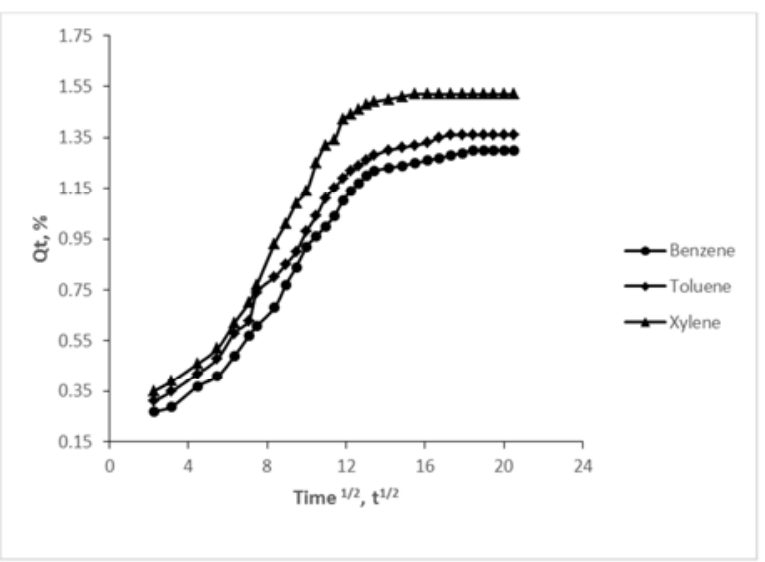

Figure 7. Effect of Penetrant size on $Q_{t}$ of Microfibre/LDPE composites at $425 \mu \mathrm{m}$.

\subsection{Swelling Properties}

Transport of solvent through polymers causes swelling of polymers. The degree of swelling, interface strength and extent of dispersion of fillers in a polymer matrix composites 
can be deduced from the swelling parameter value [18, 29]. The characteristic swelling behaviour of polymer composites can be obtained from the swelling properties like swelling index, swelling coefficient etc. Swelling index depends on the molar volumes of polymer and solvent and their cohesion energy whereas swelling coefficient is an index of the ability with which the sample swells. The swelling coefficient and swelling index of the micro fibre/LDPE composites were assessed using Eq. 2, and 3 respectively.

$$
\text { Swelling coefficient, } \beta=\frac{\text { Mass of sample at equilibrium-Initial mass of sample }}{\text { Initial mass of sample } x \text { Density of solvent }}
$$

$$
\text { Swelling Index, } \%=\frac{\text { Mass of sample at equilibrium-Initial mass of sample }}{\text { Initial mass of sample }} \times 100
$$

Tables 2 and 3 show the values of the swelling coefficient and swelling index of benzene, toluene and xylene uptake by microfibre/LDPE composites at $60^{\circ} \mathrm{C}$. It is clear from the tables that solvent uptake by the composites decreased as filler content increased and with a decrease in particle size in both modified and unmodified fibre systems. This is evidently due to the restriction exerted by the fibres at higher fibre concentrations and to good fibre/matrix interactions facilitated by higher surface area at lower particle sizes. This behaviour is same for all the other composites studied at 40 and $80^{\circ} \mathrm{C}$. However, the degree of swelling is further reduced for alkaline modified composites. This may be linked to enhanced interfacial adhesion between the matrix polymer and the fibre. It is reasonable to say that the swelling parameters are inversely related to the decrease in particle size but are temperature dependent. Undoubtedly, small particle sizes are expected to offer good composite mix with improved interfacial bonding which promotes diffusion barrier of solvents into microfibre/LDPE composites. On the other hand, the increase in swelling properties with temperature observed is possible because at elevated temperature the cohesive forces of the solvent are reduced and the rate of molecular interchange is increased leading to high rate of diffusion of solvent molecules into the composites.

Table 2. Swelling Coefficient of Microfibre/LDPE Composites at $60^{\circ} \mathrm{C}$ and

\begin{tabular}{|c|c|c|c|c|c|c|c|}
\hline \multirow{3}{*}{ Solvent } & \multirow{3}{*}{$\begin{array}{l}\text { Filler, } \\
\text { wt. \% }\end{array}$} & \multicolumn{6}{|c|}{ Swelling Coefficient, $\beta$} \\
\hline & & \multicolumn{2}{|c|}{$425 \mu \mathrm{m}$} & \multicolumn{2}{|c|}{$500 \mu \mathrm{m}$} & \multicolumn{2}{|c|}{$600 \mu \mathrm{m}$} \\
\hline & & $\mathbf{A \mu F}$ & $\mu \mathbf{F}$ & $\mathbf{A \mu F}$ & $\mu \mathrm{F}$ & $A \mu F$ & $\mu \mathbf{F}$ \\
\hline \multirow{3}{*}{ Benzene } & 10 & 1.60 & 1.71 & 1.68 & 1.80 & 1.78 & 1.91 \\
\hline & 20 & 1.54 & 1.67 & 1.62 & 1.75 & 1.70 & 1.84 \\
\hline & 30 & 1.48 & 1.61 & 1.55 & 1.69 & 1.63 & 1.78 \\
\hline \multirow{3}{*}{ Toluene } & 10 & 1.55 & 1.61 & 1.63 & 1.71 & 1.72 & 1.77 \\
\hline & 20 & 1.49 & 1.57 & 1.59 & 1.65 & 1.68 & 1.73 \\
\hline & 30 & 1.44 & 1.52 & 1.52 & 1.58 & 1.60 & 1.66 \\
\hline \multirow{3}{*}{ Xylene } & 10 & 1.46 & 1.51 & 1.55 & 1.59 & 1.63 & 1.71 \\
\hline & 20 & 1.40 & 1.47 & 1.49 & 1.57 & 1.58 & 1.69 \\
\hline & 30 & 1.33 & 1.42 & 1.43 & 1.51 & 1.54 & 1.62 \\
\hline
\end{tabular}
different particle sizes.

Table 3. Swelling Index of Microfibre/LDPE Composites at $60^{\circ} \mathrm{C}$ and

\begin{tabular}{|c|c|c|c|c|c|c|c|}
\hline \multirow{3}{*}{ Solvent } & \multirow{3}{*}{$\begin{array}{l}\text { Filler, } \\
\text { wt. \% }\end{array}$} & \multicolumn{6}{|c|}{ Swelling Index, \% } \\
\hline & & \multicolumn{2}{|c|}{$425 \mu \mathrm{m}$} & \multicolumn{2}{|c|}{$500 \mu \mathrm{m}$} & \multicolumn{2}{|c|}{$600 \mu \mathrm{m}$} \\
\hline & & $\mathbf{A} \boldsymbol{\mu} \mathbf{F}$ & $\mu \mathbf{F}$ & $\mathbf{A} \boldsymbol{\mu} \mathbf{F}$ & $\mu \mathrm{F}$ & $\mathbf{A} \boldsymbol{\mu} \mathbf{F}$ & $\mu \mathrm{F}$ \\
\hline Benzene & 10 & 10.92 & 11.70 & 11.47 & 12.32 & 12.09 & 13.03 \\
\hline
\end{tabular}
different particle sizes.

\begin{tabular}{|c|c|c|c|c|c|c|c|}
\hline \multirow{3}{*}{ Solvent } & \multirow{3}{*}{$\begin{array}{l}\text { Filler, } \\
\text { wt. \% }\end{array}$} & \multicolumn{6}{|c|}{ Swelling Index, \% } \\
\hline & & \multicolumn{2}{|c|}{$425 \mu \mathrm{m}$} & \multicolumn{2}{|c|}{$500 \mu \mathrm{m}$} & \multicolumn{2}{|c|}{$600 \mu \mathrm{m}$} \\
\hline & & $\mathbf{A \mu F}$ & $\mu \mathbf{F}$ & $\mathbf{A \mu F}$ & $\mu \mathbf{F}$ & $A \mu F$ & $\mu \mathbf{F}$ \\
\hline & 20 & 10.53 & 11.39 & 11.08 & 11.93 & 11.62 & 12.56 \\
\hline & 30 & 10.14 & 11.00 & 10.61 & 11.51 & 11.54 & 12.17 \\
\hline \multirow{4}{*}{ Toluene } & 10 & 12.33 & 12.88 & 12.97 & 13.62 & 13.71 & 14.26 \\
\hline & 20 & 11.87 & 12.51 & 12.70 & 13.16 & 13.43 & 13.80 \\
\hline & 30 & 11.50 & 12.14 & 12.14 & 12.60 & 12.77 & 13.25 \\
\hline & 10 & 13.36 & 13.89 & 14.20 & 14.63 & 14.95 & 15.69 \\
\hline \multirow{2}{*}{ Xylene } & 20 & 12.83 & 13.46 & 13.67 & 14.42 & 14.52 & 15.48 \\
\hline & 30 & 12.19 & 13.04 & 13.14 & 13.89 & 14.10 & 14.84 \\
\hline
\end{tabular}

\subsection{Kinetic Parameters}

\subsubsection{Diffusion Coefficient, (D)}

The diffusion process is a kinetic phenomenon that relates to many other factors such as the size of the solvent, the segmental mobility of the polymer, temperature etc. and sometimes characterised by partial complications. As a result, no definite universal model has been developed that clearly describes the polymer-solvent diffusion mechanism. The models used to describe the diffusion process in this study were based on solutions of Fick's law,

$$
\frac{d C}{d t}=D \frac{d^{2} C}{d x^{2}}
$$

having the following boundary conditions,

$$
\begin{gathered}
t=0-\frac{h}{2}<x<\frac{h}{2}, c=0 ; t>0, x=0, \frac{d c}{d x}=0 ; \\
t>0, x= \pm \frac{h}{2}, c=0
\end{gathered}
$$

where $c$ is the concentration, $t$ is time, $x$ is position in the composite, $h$ is the total thickness of the composite sheet, and $\mathrm{D}$ is the diffusion coefficient. If there is a negligible concentration dependence of diffusivity over the concentration interval studied, a value of mutual diffusion coefficient D can be calculated using Eq.5 [42].

$$
\frac{Q_{t}}{Q_{\infty}}=1-\sum_{x=0}^{\infty} \frac{8}{(2 x+1)^{2} \pi^{2}} e^{-(2 x+1)^{2} \pi^{2}\left(\frac{D_{t}}{h^{2}}\right)}
$$

where $\mathrm{Q}_{t}$ is the mass uptake of the composite in a solvent at $t$, and $\mathrm{Q}_{\infty}$ is the mass uptake when the composite has reached equilibrium. To understand the modeling of the diffusion process in polymer composites and polymeric hydrogels, several researchers have used three well-accepted approximations of Eq. (5): (i) the 'early-time' approximation 
(Eq. (6)) [43], (ii) the 'late-time' approximation (Eq. (7)) and (iii) the Etters approximation (Eq. (8)) [44].

$$
\begin{gathered}
\frac{Q_{t}}{Q_{\infty}}=\left(\frac{4}{\mathrm{~h}}\right)\left(\frac{\mathrm{Dt}}{\pi}\right)^{\frac{1}{2}} \\
\frac{Q_{t}}{Q_{\infty}}=1-\frac{8}{\pi^{2}} \exp { }^{\left(-\frac{D \pi^{2} t}{h^{2}}\right)} \\
\frac{Q_{t}}{Q_{\infty}}=\left[1-\exp \left(-\mathrm{k}\left(\frac{\mathrm{Dt}}{\mathrm{h}^{2}}\right)^{\mathrm{p}}\right)\right]^{\frac{1}{b}}
\end{gathered}
$$

For the Etters model, $\mathrm{p}, \mathrm{b}$, and $\mathrm{k}$ were 1.3390, 2.6001, and 10.5449, respectively [45]. To determine the diffusion coefficient of microfibre/LDPE composites, we applied equation 6 , the "early- time" approximation which fits the sorption process. A plot of $\mathrm{Q}_{t} \mathrm{vs}$. $\mathrm{t}^{1 / 2}$ gives a curve with the initial linear portion. Thus, D can be calculated on the rearrangement of Eq. 6 as shown in Eq. 9.

$$
\mathrm{D}=\pi\left(\frac{\mathrm{h} \theta}{4 \mathrm{Q}_{\infty}}\right)^{2}
$$

where $\theta$ is the slope of the linear portion of the sorption curve of the plot of $\% Q_{t}$ against $t^{1 / 2}$.

The variation of diffusion coefficient for the different fibre contents and solvents at all the temperatures studied is given in Table 4. The diffusion coefficient was found to be inversely related to both temperature and fibre content. A small diffusion coefficient indicates that only a small amount of solvent can be absorbed by the sample. The diffusion coefficient is lower for treated fibre and lowest for $400 \mu \mathrm{m}$ particle size reinforced composites. Table 4 also shows that Diffusion coefficient values generally increase with an increase in the molecular

\begin{tabular}{|c|c|c|c|c|c|c|c|c|}
\hline \multirow[t]{3}{*}{ Solvent } & \multirow[t]{3}{*}{ Temp. ${ }^{\circ} \mathrm{C}$} & \multirow[t]{3}{*}{ Filler, wt. \% } & \multicolumn{6}{|c|}{ D x $10^{-6}, \mathrm{Cm}^{2} / \mathrm{sec}$} \\
\hline & & & \multicolumn{2}{|c|}{$425 \mu \mathrm{m}$} & \multicolumn{2}{|c|}{$500 \mu \mathrm{m}$} & \multicolumn{2}{|c|}{$600 \mu \mathrm{m}$} \\
\hline & & & $\mathbf{A} \boldsymbol{F} \mathbf{F}$ & $\mu \mathbf{F}$ & $\mathbf{A} \mu \mathrm{F}$ & $\mu \mathbf{F}$ & $\mathbf{A \mu F}$ & $\mu \mathbf{F}$ \\
\hline \multirow{8}{*}{ Benzene } & \multirow{3}{*}{40} & 10 & 4.42 & 4.71 & 4.88 & 5.16 & 5.40 & 5.67 \\
\hline & & 20 & 4.26 & 4.46 & 4.72 & 4.93 & 5.27 & 5.47 \\
\hline & & 30 & 3.94 & 4.09 & 4.43 & 4.57 & 4.95 & 5.10 \\
\hline & \multirow[b]{2}{*}{60} & 10 & 4.24 & 4.59 & 4.72 & 5.07 & 5.26 & 5.60 \\
\hline & & 20 & 4.08 & 4.31 & 4.56 & 4.79 & 5.09 & 5.31 \\
\hline & \multirow{3}{*}{80} & 10 & 4.23 & 4.46 & 4.74 & 4.95 & 5.29 & 5.51 \\
\hline & & 20 & 4.02 & 4.23 & 4.48 & 4.77 & 4.97 & 5.33 \\
\hline & & 30 & 3.79 & 3.94 & 4.25 & 4.42 & 4.77 & 4.88 \\
\hline \multirow{7}{*}{ Toluene } & \multirow{3}{*}{40} & 10 & 4.96 & 5.21 & 5.47 & 5.83 & 6.04 & 3.83 \\
\hline & & 20 & 4.67 & 5.18 & 5.24 & 5.68 & 5.81 & 6.29 \\
\hline & & 30 & 4.50 & 4.62 & 4.97 & 5.15 & 6.27 & 5.73 \\
\hline & 60 & 10 & 4.84 & 5.24 & 5.41 & 5.69 & 6.04 & 6.31 \\
\hline & \multirow{3}{*}{80} & 10 & 4.82 & 4.93 & 5.34 & 5.49 & 6.10 & 6.10 \\
\hline & & 20 & 4.57 & 4.76 & 5.12 & 5.33 & 5.77 & 5.97 \\
\hline & & 30 & 4.28 & 4.42 & 4.74 & 4.99 & 5.39 & 5.62 \\
\hline \multirow{9}{*}{ Xylene } & \multirow{3}{*}{40} & 10 & 4.83 & 5.23 & 5.37 & 5.76 & 5.78 & 6.43 \\
\hline & & 20 & 4.64 & 4.96 & 5.15 & 5.57 & 5.63 & 6.24 \\
\hline & & 30 & 4.59 & 4.76 & 5.02 & 5.35 & 5.53 & 6.02 \\
\hline & \multirow{3}{*}{60} & 10 & 4.88 & 4.91 & 5.43 & 5.52 & 6.07 & 6.25 \\
\hline & & 20 & 4.71 & 4.76 & 5.22 & 5.40 & 5.74 & 6.04 \\
\hline & & 30 & 4.40 & 4.59 & 5.18 & 5.13 & 5.41 & 5.78 \\
\hline & \multirow{3}{*}{80} & 10 & 4.76 & 5.65 & 5.36 & 6.23 & 6.35 & 6.95 \\
\hline & & 20 & 4.54 & 5.29 & 5.01 & 5.45 & 6.12 & 6.12 \\
\hline & & 30 & 4.29 & 5.54 & 5.19 & 6.21 & 6.08 & 6.08 \\
\hline
\end{tabular}
mass of the solvent used, where the order in the molecular mass of the solvents is xylene $>$ toluene $>$ benzene.

Table 4. Diffusion values of Microfibre/LDPE Composites at different temperatures and mesh sizes.

This order is also in the direction of increasing density and solubility parameter of the solvents as shown in Table 1 . The higher diffusion coefficient observed for xylene could be due to the closeness of its solubility parameter $(18.2 \mathrm{MPa})$ to that of polyethylene (16.5 MPa). Thus, strong interaction occurs if the polymer and solvent have close solubility parameter values. The solubility parameter is a very important factor that controls solubility response of polymers in solvents. That the present study has shown a dependence of diffusivity on the molecular mass of solvents. This is in agreement with the findings of some authors $[31,32]$ who reported a direct dependence of diffusion coefficient on the molecular weight and solubility parameter of solvents. The decrease in diffusion coefficient with an increase in temperature as earlier stated may be attributed to the fact that the diffusing molecules are defacilitated by the higher thermal energies at the increased temperature. However, the increase in the diffusion coefficient with an increase in sorption temperature has been reported by some authors $[38,46]$. The table shows that at any filler content, solvent, and temperature investigated, the diffusion coefficient value decrease with a decrease in filler particle size and treatment as well. This is 
expected since diffusivity depends on the free volume within the polymer and the segmental mobility of polymer chains. Therefore, the small sized fibre filled composites sorb less solvent than the untreated counterparts. The diffusion coefficient is also related to penetration rate $\left(\mathrm{P}_{\mathrm{r}}\right)$ as shown in equation 10. The penetration rate may be expressed by the rate of the advancing swollen fronts which could be calculated from the linear portion of the sorption curve.

$$
P_{r}=\frac{2 \sqrt{D}}{\sqrt{\pi}}
$$

The penetration rate of the solvents taking at $40^{\circ} \mathrm{C}$ decreases with the increase in filler content, decrease in particle size and treatment as given in Table 5.

Table 5. Penetration Rate of Microfibre/LDPE Composites at $40^{\circ} \mathrm{C}$ and different particle sizes.

\begin{tabular}{|c|c|c|c|c|c|c|c|c|}
\hline \multirow[t]{3}{*}{ Solvent } & \multirow[t]{3}{*}{ Temp. ${ }^{\circ} \mathrm{C}$} & Filler, wt. \% & \multicolumn{6}{|c|}{ Penetration rate, $\mathrm{x}^{10^{-3}} \mathrm{cms}^{-1 / 2}$} \\
\hline & & & \multicolumn{2}{|c|}{$425 \mu \mathrm{m}$} & \multicolumn{2}{|c|}{$500 \mu \mathrm{m}$} & \multicolumn{2}{|c|}{$600 \mu \mathrm{m}$} \\
\hline & & & $\mathbf{A} \mu \mathbf{F}$ & $\mu \mathbf{F}$ & $\mathbf{A \mu F}$ & $\mu \mathbf{F}$ & $\mathbf{A} \mu \mathrm{F}$ & $\mu \mathbf{F}$ \\
\hline \multirow{4}{*}{ Benzene } & & 10 & 2.37 & 2.45 & 2.49 & 2.56 & 2.62 & 2.69 \\
\hline & & 20 & 2.33 & 2.41 & 2.45 & 2.51 & 2.59 & 2.64 \\
\hline & & 30 & 2.24 & 2.28 & 2.37 & 2.41 & 2.51 & 2.55 \\
\hline & & 10 & 2.51 & 2.57 & 2.64 & 2.72 & 2.77 & 2.07 \\
\hline \multirow[t]{2}{*}{ Toluene } & 40 & 20 & 2.44 & 2.57 & 2.58 & 2.69 & 2.72 & 2.83 \\
\hline & & 10 & 2.48 & 2.58 & 2.61 & 2.71 & 2.71 & 2.86 \\
\hline \multirow[t]{2}{*}{ Xylene } & & 20 & 2.43 & 2.51 & 2.56 & 2.66 & 2.68 & 2.82 \\
\hline & & 30 & 2.42 & 2.46 & 2.53 & 2.61 & 2.65 & 2.77 \\
\hline
\end{tabular}

Similar trends were also obtained for 60 and $80^{\circ} \mathrm{C}$. These results are similar to the results obtained for diffusion coefficients calculated for the composites at various filler contents. It is worthy to state that the alkali treated samples and samples with lowest particle size showed lowest values for all the parameters studied. This may be attributed to improved bond adhesion between the matrix and fibre.

\subsubsection{Sorption Coefficient (S)}

The sorption coefficient indicates the maximum saturation sorption value and it is calculated using the relation [42, 47].

$$
S=\frac{\text { Equilibrium swelling weight }}{\text { Initial weight of sample }}
$$

The sorption coefficient is a kinetic parameter which depends on the strength of the interactions in the composite penetrant system. The sorption coefficient (S) which was obtained from the plateau regions of the equilibrium sorption curves is presented in Table 6 for the micro fibre/LDPE composites in different solvents and at different temperatures. From the table, the sorption coefficient increases with micro fibre content, filler particle size and temperature in the composite for a given solvent but decreases with treatment indicating that sorption is somewhat restricted by the alkali treatment of filler. This observation agrees with the findings of Michaels et al [48] who reported that the solubility of solvents in polymers increases with an increase in sorption temperature. Johnson and Thomas [46], also in their sorption studies reported that the sorption coefficient increased with increase in sorption temperature and in filler particle size too. Table 6 also shows that the sorption coefficient is highest in benzene, followed by toluene, and then xylene at all temperatures. However, the above results are in contrast to the findings of some authors $[18,40]$ who reported a decrease in sorption coefficient with an increase in filler content.

\subsubsection{Permeation Coefficient (P)}

The permeation coefficient of a solvent in filled polymers depends on the diffusion and sorption behaviour of the solvent in the filled polymers. The permeation coefficient $(\mathrm{P})$ of the aromatic solvents in the composites was obtained using the following expression;

Permeation coefficient $(\mathrm{P})=$ Diffusion coefficient (D) $x$ Sorption coefficient $(\mathrm{S})$

The values of $P$ are given in Table 7. The permeation coefficients were generally observed to increase with an increase in sorption temperature and particle size but a decrease with filler content in all filled composites under study. Obviously, higher temperatures will tend to make more flexible the polymer chains thereby facilitating the solvent permeability. Unnikrishnan et al [47] who investigated the diffusion of aromatic hydrocarbons through filled NR found that the permeability values of NR-penetrant systems followed the same trend as that of diffusivity. Also, Johnson and Thomas [46] who studied the transport of n-alkanes through epoxidized natural rubber found that the permeability coefficient increased with temperature. The trend is the same in this study except that permeation coefficient is highest in toluene, followed by xylene, and then benzene of the composites in aromatic solvents. The permeation coefficient is lower for the alkali treated and decreases as a function of filler concentration. This is because alkali-treated filler restricts the polymer chain mobility and the movement of solvent molecules between the polymer chains. The equilibrium solvent uptake has been found to closely follow the trend of diffusion, sorption, and permeation coefficients, indicating that the transport phenomenon is controlled by these three parameters $[39,49]$. 
Table 6. Sorption values of Microfibre/LDPE Composites at different temperatures and mesh sizes.

\begin{tabular}{|c|c|c|c|c|c|c|c|c|}
\hline \multirow{3}{*}{ Solvent } & \multirow{3}{*}{ Temp. ${ }^{\circ} \mathbf{C}$} & \multirow{3}{*}{ Filler, wt. \% } & \multicolumn{6}{|c|}{ Sorption, S, \% } \\
\hline & & & \multicolumn{2}{|c|}{$425 \mu \mathrm{m}$} & \multicolumn{2}{|l|}{$500 \mu \mathrm{m}$} & \multicolumn{2}{|c|}{$600 \mu \mathrm{m}$} \\
\hline & & & $\mathbf{A \mu F}$ & $\mu \mathbf{F}$ & $\mathbf{A \mu F}$ & $\mu \mathbf{F}$ & $\mathbf{A} \boldsymbol{\mu} \mathbf{F}$ & $\mu \mathbf{F}$ \\
\hline \multirow{9}{*}{ Benzene } & \multirow{3}{*}{40} & 10 & 3.51 & 3.79 & 3.68 & 3.95 & 3.87 & 4.15 \\
\hline & & 20 & 3.59 & 3.87 & 3.79 & 4.06 & 4.01 & 4.26 \\
\hline & & 30 & 3.73 & 4.01 & 3.93 & 4.23 & 4.15 & 4.45 \\
\hline & \multirow{3}{*}{60} & 10 & 3.59 & 3.90 & 3.76 & 4.09 & 3.95 & 4.31 \\
\hline & & 20 & 3.73 & 4.04 & 3.93 & 4.23 & 4.12 & 4.45 \\
\hline & & 30 & 3.87 & 4.15 & 4.06 & 4.37 & 4.28 & 4.62 \\
\hline & \multirow{3}{*}{80} & 10 & 3.79 & 4.12 & 3.95 & 4.31 & 4.15 & 4.53 \\
\hline & & 20 & 3.87 & 4.26 & 4.06 & 4.51 & 4.23 & 4.81 \\
\hline & & 30 & 4.04 & 4.42 & 4.23 & 4.67 & 4.42 & 4.98 \\
\hline \multirow{9}{*}{ Toluene } & \multirow{3}{*}{40} & 10 & 3.39 & 3.50 & 3.55 & 3.69 & 3.75 & 3.92 \\
\hline & & 20 & 3.50 & 3.66 & 3.66 & 3.86 & 3.83 & 4.08 \\
\hline & & 30 & 3.66 & 3.80 & 3.80 & 4.00 & 4.00 & 4.20 \\
\hline & \multirow{3}{*}{60} & 10 & 3.50 & 3.69 & 3.69 & 3.83 & 3.89 & 4.03 \\
\hline & & 20 & 3.61 & 4.20 & 3.86 & 4.00 & 4.08 & 3.80 \\
\hline & & 30 & 3.75 & 3.92 & 3.94 & 4.14 & 4.17 & 4.34 \\
\hline & \multirow{3}{*}{80} & 10 & 3.64 & 3.78 & 3.80 & 3.97 & 4.03 & 4.17 \\
\hline & & 20 & 3.75 & 3.92 & 3.94 & 4.11 & 4.17 & 4.34 \\
\hline & & 30 & 3.89 & 4.06 & 4.06 & 4.28 & 4.31 & 4.50 \\
\hline \multirow{9}{*}{ Xylene } & \multirow{3}{*}{40} & 10 & 3.29 & 3.42 & 3.50 & 3.64 & 3.72 & 3.88 \\
\hline & & 20 & 3.15 & 3.29 & 3.40 & 3.50 & 3.56 & 3.75 \\
\hline & & 30 & 3.02 & 3.21 & 3.23 & 3.40 & 3.40 & 3.61 \\
\hline & \multirow{3}{*}{60} & 10 & 3.40 & 3.53 & 3.61 & 3.72 & 3.80 & 3.99 \\
\hline & & 20 & 3.26 & 3.42 & 3.48 & 3.67 & 3.69 & 3.94 \\
\hline & & 30 & 3.10 & 3.32 & 3.34 & 3.53 & 3.59 & 3.77 \\
\hline & \multirow{3}{*}{80} & 10 & 3.53 & 3.69 & 3.69 & 3.88 & 3.91 & 4.10 \\
\hline & & 20 & 3.42 & 3.59 & 3.59 & 3.75 & 3.77 & 3.96 \\
\hline & & 30 & 3.32 & 3.50 & 3.45 & 3.67 & 3.61 & 3.83 \\
\hline
\end{tabular}

Table 7. Permeation values of Microfibre/LDPE Composites at different temperatures and mesh sizes.

\begin{tabular}{|c|c|c|c|c|c|c|c|c|}
\hline \multirow[t]{3}{*}{ Solvent } & \multirow[t]{3}{*}{ Temp. ${ }^{\circ} \mathrm{C}$} & \multirow[t]{3}{*}{ Filler, wt. \% } & \multicolumn{6}{|c|}{ Permeation, $\mathrm{P} \times 10^{-6}, \mathrm{Cm}^{2} / \mathrm{sec}$} \\
\hline & & & \multicolumn{2}{|c|}{$425 \mu \mathrm{m}$} & \multirow{2}{*}{$\begin{array}{l}500 \mu \mathrm{m} \\
\mathrm{AuF}\end{array}$} & & \multicolumn{2}{|c|}{$600 \mu \mathrm{m}$} \\
\hline & & & $\mathbf{A \mu F}$ & $\mu \mathbf{F}$ & & $\mu \mathrm{F}$ & $\mathbf{A \mu F}$ & $\mu \mathbf{F}$ \\
\hline \multirow{9}{*}{ Benzene } & \multirow{3}{*}{40} & 10 & 15.51 & 17.85 & 17.96 & 20.38 & 20.90 & 23.53 \\
\hline & & 20 & 15.29 & 17.26 & 17.89 & 20.02 & 21.13 & 23.30 \\
\hline & & 30 & 14.70 & 16.40 & 17.41 & 19.33 & 20.54 & 22.69 \\
\hline & \multirow{3}{*}{60} & 10 & 15.22 & 17.90 & 17.75 & 20.74 & 20.78 & 24.14 \\
\hline & & 20 & 15.22 & 17.41 & 17.92 & 20.26 & 20.97 & 23.63 \\
\hline & & 30 & 14.86 & 16.27 & 17.54 & 19.27 & 20.80 & 22.82 \\
\hline & \multirow{3}{*}{80} & 10 & 16.03 & 18.37 & 18.72 & 21.33 & 21.95 & 24.96 \\
\hline & & 20 & 15.56 & 18.02 & 18.19 & 21.52 & 21.02 & 25.64 \\
\hline & & 30 & 15.31 & 17.41 & 17.98 & 20.64 & 21.08 & 24.30 \\
\hline \multirow{9}{*}{ Toluene } & \multirow{3}{*}{40} & 10 & 16.81 & 18.23 & 19.42 & 21.51 & 22.65 & 13.25 \\
\hline & & 20 & 16.34 & 18.96 & 19.18 & 21.92 & 22.25 & 25.66 \\
\hline & & 30 & 16.47 & 17.56 & 18.89 & 20.60 & 25.08 & 24.07 \\
\hline & \multirow{3}{*}{60} & 10 & 16.94 & 19.34 & 19.96 & 21.79 & 23.50 & 25.43 \\
\hline & & 20 & 16.48 & 26.08 & 20.07 & 22.36 & 23.83 & 19.08 \\
\hline & & 30 & 16.46 & 17.44 & 19.42 & 20.74 & 23.23 & 24.30 \\
\hline & \multirow{3}{*}{80} & 10 & 17.54 & 18.63 & 20.29 & 21.79 & 24.22 & 25.44 \\
\hline & & 20 & 17.14 & 18.66 & 20.17 & 21.91 & 24.06 & 25.91 \\
\hline & & 30 & 16.65 & 17.94 & 19.24 & 21.36 & 23.23 & 25.29 \\
\hline \multirow{9}{*}{ Xylene } & \multirow{3}{*}{40} & 10 & 15.89 & 17.89 & 18.79 & 20.97 & 21.50 & 24.95 \\
\hline & & 20 & 14.64 & 16.33 & 17.49 & 19.52 & 20.02 & 23.40 \\
\hline & & 30 & 13.86 & 15.28 & 16.21 & 18.19 & 18.80 & 21.73 \\
\hline & \multirow{3}{*}{60} & 10 & 16.59 & 17.33 & 19.60 & 20.53 & 23.07 & 24.94 \\
\hline & & 20 & 15.35 & 16.29 & 18.17 & 19.80 & 21.22 & 23.77 \\
\hline & & 30 & 13.64 & 15.24 & 17.30 & 18.11 & 19.42 & 21.79 \\
\hline & \multirow{3}{*}{80} & 10 & 16.80 & 20.85 & 19.78 & 24.17 & 24.83 & 28.49 \\
\hline & & 20 & 15.55 & 18.98 & 17.98 & 20.42 & 20.86 & 24.24 \\
\hline & & 30 & 14.24 & 19.39 & 17.90 & 22.79 & 19.46 & 23.29 \\
\hline
\end{tabular}




\subsection{Energy of Activation}

The temperature dependence of transport parameters (diffusion and permeation) can be used to evaluate the activation energy for the diffusion and permeation processes using the Arrhenius relation, Eq. 13 [50];

$$
\log X=\log X_{o}-\frac{E_{X}}{2.303 R T}
$$

where, $\mathrm{X}$ is $\mathrm{P}$ or $\mathrm{D}$ and $\mathrm{X}_{0}$ represents $\mathrm{P}_{0}$ or $\mathrm{D}_{0}$, which are constants; $E_{x}$ is the activation energy, $R$, the universal gas constant and $\mathrm{T}$, the absolute temperature. From the slopes of the Arrhenius plots of $\log \mathrm{D}$ and $\log \mathrm{P}$ against $1 / \mathrm{T}$, activation energies of diffusion and permeation were calculated by linear regression analysis. The values of $E_{D}$ and
$E_{P}$ are given in Table 8. The activation energy of permeation $E_{P}$ was found to be generally greater than that of the activation energy of diffusion $\mathrm{E}_{\mathrm{D}}$ and was highest in xylene as expected in this study. No definite order was observed in the energies of activation with the filler contents, particle size or treatment. The negative value of the activation energy suggested that the rise in the solution temperature did not favour solvents absorption into microfibre/LDPE composites. The negative value also indicates an exothermic reaction and the low value of the activation energy suggests that the absorption process of solvents into LDPE filled composites might be by physical absorption. It means that the ratelimiting step of solvents absorption into microfibre/LDPE composites involved predominantly a physical process.

Table 8. Values of activation energy $\left(E_{D}\right.$ and $\left.E_{P}\right)$ of Microfibre/LDPE Composites.

\begin{tabular}{|c|c|c|c|c|c|c|c|c|c|c|c|c|c|}
\hline \multirow[t]{3}{*}{ Solvent } & \multirow[t]{3}{*}{ Filler Wt. \% } & \multicolumn{6}{|c|}{ 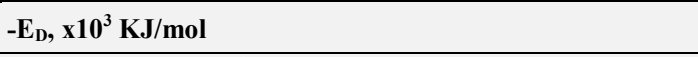 } & \multicolumn{6}{|c|}{$E_{P}, x 10^{3} \mathrm{KJ} / \mathrm{mol}$} \\
\hline & & \multicolumn{2}{|c|}{$425 \mu \mathrm{m}$} & \multicolumn{2}{|c|}{$500 \mu \mathrm{m}$} & \multicolumn{2}{|c|}{$600 \mu \mathrm{m}$} & \multicolumn{2}{|c|}{$400 \mu \mathrm{m}$} & \multicolumn{2}{|c|}{$500 \mu \mathrm{m}$} & \multicolumn{2}{|c|}{$600 \mu \mathrm{m}$} \\
\hline & & $A \mu F$ & $\mu \mathbf{F}$ & $\mathbf{A \mu F}$ & $\boldsymbol{\mu} \mathbf{F}$ & $\mathbf{A \mu F}$ & $\mu \mathbf{F}$ & $\mathbf{A \mu F}$ & $\boldsymbol{\mu F}$ & $\mathbf{A} \boldsymbol{\mu F}$ & $\mu \mathbf{F}$ & $\mathbf{A \mu F}$ & $\mu \mathbf{F}$ \\
\hline \multirow{3}{*}{ Benzene } & 10 & 1.08 & 0.56 & 1.06 & 0.56 & 1.06 & 1.08 & 1.03 & 1.01 & 1.03 & 1.55 & 0.54 & 1.03 \\
\hline & 20 & 1.59 & 1.06 & 1.57 & 0.54 & 1.06 & 0.54 & 0.50 & 1.03 & 0.52 & 1.57 & 0.50 & 2.07 \\
\hline & 30 & 1.08 & 1.06 & 0.56 & 0.52 & 0.54 & 0.52 & 1.01 & 0.47 & 1.57 & 1.06 & 1.03 & 1.57 \\
\hline \multirow{3}{*}{ Toluene } & 10 & 1.16 & 1.07 & 1.04 & 0.70 & 3.47 & 0.43 & 0.20 & 0.46 & 0.44 & 0.83 & -1.78 & 1.10 \\
\hline & 20 & 0.47 & 1.90 & 0.52 & 1.41 & 0.15 & 1.20 & 1.11 & -0.35 & 1.18 & 0.02 & 1.82 & 0.27 \\
\hline & 30 & 0.91 & 1.23 & 0.53 & 1.37 & 0.10 & +1.38 & 0.94 & 0.52 & 1.01 & 0.27 & 1.53 & 15.30 \\
\hline \multirow{3}{*}{ Xylene } & 10 & 1.59 & -3.30 & -1.52 & -3.29 & -3.09 & -3.21 & 1.34 & 3.38 & 1.18 & 3.14 & 3.33 & 3.00 \\
\hline & 20 & 0.48 & -1.41 & 0.58 & 0.51 & 0.39 & 0.49 & 1.39 & 3.36 & 0.65 & 1.05 & 0.93 & 0.84 \\
\hline & 30 & 0.30 & -3.37 & 0.78 & -3.32 & 0.31 & -1.68 & 0.61 & 5.38 & 2.28 & 5.07 & 0.81 & 1.55 \\
\hline
\end{tabular}

\subsection{Transport Mechanisms}

To evaluate the mechanism of sorption, we adopted a Fickian model. The most common and the easiest means of analysis. To investigate its applicability to this study, a complementary modelling method for the early-time approximation power law equation [51] was used,

$$
\frac{\mathrm{Q}_{\mathrm{t}}}{\mathrm{Q}_{\infty}}=K \mathrm{t}^{\mathrm{n}}
$$

where $\mathrm{Q}_{\mathrm{t}}$ and $\mathrm{Q}_{\infty}$ are the mol \% sorption at time $\mathrm{t}$, and equilibrium, respectively. $k$ is a constant that depends upon the structural characteristics of the polymer, in addition to its interaction with the solvent. The value of the exponent, $n$, indicates the nature of the transport mechanism. When the value of $n=0.5$, the mechanism of transport is said to be Fickian and this occurs when the rate of diffusion of the penetrant molecule is much less than the relaxation rate of the polymer chains. When $n=1$, it is termed as non-Fickian (case II-relaxation controlled) which occurs when the rate of diffusion of the penetrant molecule is much greater than the relaxation process. When the value of $n$ between 0.5 and 1 indicates anomalous transport behaviour and it is since the rate of diffusion of the penetrant molecule and the relaxation rate of the polymer are similar. Super-case II transport occurs when $n>1.0$; in that case, the diffusion rate is timedependent and it is pseudo-Fickian (less Fickian behaviour) when $n<0.5$ Equation (14) can be linearized by taking logarithms of both sides such that,

$$
\log \left(\frac{Q_{t}}{Q_{\infty}}\right)=\log k+n \log t
$$

The values of $n$ and $k$ for the microfibre/LDPE composites in benzene, toluene and xylene at $60^{\circ} \mathrm{C}$ are shown in Table 9 and were got by regression analysis of the plot of $\log \left(\mathrm{Q}_{\mathrm{t}} / \mathrm{Q}_{\infty}\right)$ against $\log \mathrm{t}$. The trend is the same for composites at 40 and $80^{\circ} \mathrm{C}$. From Table 9, the values of $n$ obtained are Fickian and lie in the range $0.4<n \leq$ 0.5 for the composites at different temperatures, filler content, particle sizes and treatment. This observation had been reported elsewhere in the literature [29, 52, 53]. Moreover, the values of $n$ did not show any relationship to the amount filler, its treatment and particle size. The values of $k$ decreased with increase in filler content and are higher for the untreated composites but showed no dependence on particle size and temperature. This might be linked to the higher interfacial adhesion between the treated fibres and the matrix. However, Kumnuantip and Sombatsompop [54] in their studies reported a general increase of $k$ with increase in reclaimed natural rubber. 
Table 9. Values of $n$ and $\mathrm{k}\left(\mathrm{g} / \mathrm{g} / \mathrm{min}^{-n}\right)$ of Microfibre/LDPE Composites at $60^{\circ} \mathrm{C}$.

\begin{tabular}{|c|c|c|c|c|c|c|c|c|c|c|c|c|c|c|}
\hline \multirow{3}{*}{ Solvent } & \multirow{3}{*}{ Temp., ${ }^{\circ} \mathrm{C}$} & \multirow{3}{*}{ Filler, wt. \% } & \multicolumn{6}{|l|}{ n } & \multicolumn{4}{|l|}{$\mathbf{k}$} & \multirow{2}{*}{\multicolumn{2}{|c|}{$600 \mu \mathrm{m}$}} \\
\hline & & & \multicolumn{2}{|c|}{$425 \mu \mathrm{m}$} & \multicolumn{2}{|c|}{$500 \mu \mathrm{m}$} & \multicolumn{2}{|c|}{$600 \mu \mathrm{m}$} & \multicolumn{2}{|c|}{$425 \mu \mathrm{m}$} & \multicolumn{2}{|c|}{$500 \mu \mathrm{m}$} & & \\
\hline & & & $\mathbf{A} \boldsymbol{\mu} \mathbf{F}$ & $\mu \mathbf{F}$ & $\mathbf{A \mu} \mathbf{F}$ & $\mu \mathrm{F}$ & $\mathbf{A} \boldsymbol{\mu} \mathbf{F}$ & $\mu \mathrm{F}$ & $\mathbf{A} \boldsymbol{\mu} \mathbf{F}$ & $\mu \mathbf{F}$ & $\mathbf{A} \boldsymbol{\mu} \mathbf{F}$ & $\mu \mathrm{F}$ & $\mathrm{A \mu F}$ & $\mu \mathrm{F}$ \\
\hline \multirow{4}{*}{ Benzene } & & 10 & 0.42 & 0.41 & 0.44 & 0.42 & 0.45 & 0.44 & 0.098 & 0.109 & 0.092 & 0.103 & 0.086 & 0.097 \\
\hline & & 20 & 0.44 & 0.44 & 0.45 & 0.45 & 0.47 & 0.46 & 0.089 & 0.093 & 0.083 & 0.090 & 0.079 & 0.085 \\
\hline & & 30 & 0.46 & 0.46 & 0.47 & 0.47 & 0.48 & 0.48 & 0.081 & 0.083 & 0.077 & 0.081 & 0.074 & 0.077 \\
\hline & & 10 & 0.43 & 0.41 & 0.45 & 0.43 & 0.47 & 0.44 & 0.091 & 0.104 & 0.086 & 0.097 & 0.080 & 0.092 \\
\hline \multirow[t]{3}{*}{ Toluene } & 60 & 20 & 0.45 & 0.45 & 0.47 & 0.48 & 0.49 & 0.48 & 0.084 & 0.084 & 0.077 & 0.080 & 0.072 & 0.077 \\
\hline & & 30 & 0.47 & 0.47 & 0.49 & 0.48 & 0.50 & 0.49 & 0.074 & 0.077 & 0.070 & 0.076 & 0.066 & 0.072 \\
\hline & & 10 & 0.45 & 0.43 & 0.46 & 0.45 & 0.49 & 0.47 & 0.084 & 0.094 & 0.079 & 0.089 & 0.074 & 0.082 \\
\hline \multirow[t]{2}{*}{ Xylene } & & 20 & 0.47 & 0.45 & 0.49 & 0.47 & 0.50 & 0.49 & 0.073 & 0.086 & 0.068 & 0.080 & 0.064 & 0.074 \\
\hline & & 30 & 0.49 & 0.47 & 0.50 & 0.48 & 0.50 & 0.50 & 0.068 & 0.079 & 0.063 & 0.074 & 0.058 & 0.069 \\
\hline
\end{tabular}

\subsection{Thermodynamic Parameters}

Van't Hoff's relation was used to determine thermodynamic parameters of sorption such as enthalpy of absorption $\left(\Delta \mathrm{H}_{\mathrm{s}}\right)$ and entropy of absorption $\left(\Delta \mathrm{S}_{\mathrm{s}}\right)$.

$$
\log \mathrm{K}_{\mathrm{s}}=\frac{\Delta \mathrm{S}_{\mathrm{s}}}{2.303 \mathrm{R}}-\frac{\Delta \mathrm{H}_{\mathrm{s}}}{2.303 \mathrm{RT}}
$$

where, $\mathrm{K}_{\mathrm{s}}$ is the equilibrium sorption constant, which is given by,

$$
\mathrm{K}_{\mathrm{S}}=\frac{\text { Number of moles of the solvent absorbed at equilibrium }}{\text { Mass of the composite sample }}
$$

The values of $\Delta \mathrm{H}_{\mathrm{s}}$ and $\Delta \mathrm{S}_{\mathrm{s}}$ were obtained by the regression analysis of the plots of Log Ks Vs $1 / \mathrm{T}$ and are given in Tables 10-12 for all the temperatures studied. From the tables, the calculated $\Delta \mathrm{H}_{\mathrm{s}}$ is generally positive and showed no relationship to the penetrant size, filler content, filler particle size or treatment. Enthalpy of absorption $\left(\Delta \mathrm{H}_{\mathrm{s}}\right)$ is a is a composite parameter involving contributions from (i) Henry's law, which is needed for the formation of a site and the dissolution of the species into that site and (ii) Langmuir's (hole-filling) sorption mechanism, in which case, the site already exists in the polymer matrix and sorption by hole-filling gives exothermic heat of sorption. In other words, the positive $\Delta H_{s}$ values obtained for the aromatic solvents suggest that sorption, in this case, is dominated by Henry's mode with endothermic contributions. This implies that the sorption proceeds through the creation of new sites or pores in the polymer [55]. From Tables $10-12$ also, $\Delta \mathrm{S}_{\mathrm{s}}$ values are negative and did not show any relationship to the filler content, penetrant size, particle size or treatment indicating that the sorption is not spontaneous or the rate of diffusion is very low. The negative entropy values indicate the orderliness of the sorbed molecule in the matrix [56].

Table 10. Values of enthalpy of absorption $\left(\Delta H_{s}\right)$, entropy of absorption $\left(\Delta S_{s}\right)$, and Gibbs free energy $\left(\Delta G_{s}\right)$ of Microfibre/LDPE Composites for $425 \mu \mathrm{m}$.

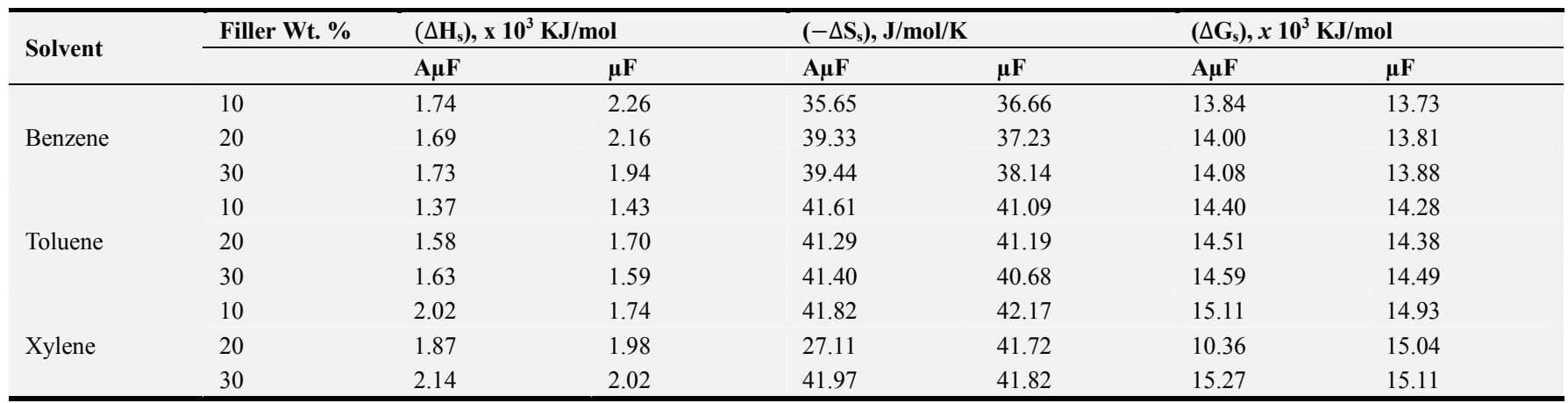

\begin{tabular}{|c|c|c|c|c|c|c|c|}
\hline \multirow{2}{*}{ Solvent } & \multirow[t]{2}{*}{ Filler Wt. \% } & \multicolumn{2}{|c|}{$\left(\Delta \mathrm{H}_{\mathrm{s}}\right), \times 10^{3} \mathrm{KJ} / \mathrm{mol}$} & \multicolumn{2}{|c|}{$\left(-\Delta \mathbf{S}_{\mathrm{s}}\right), \mathrm{J} / \mathrm{mol} / \mathrm{K}$} & \multicolumn{2}{|c|}{$\left(\Delta G_{\mathrm{s}}\right), x 10^{3} \mathrm{KJ} / \mathrm{mol}$} \\
\hline & & $\mathbf{A} \mu \mathrm{F}$ & $\mu \mathbf{F}$ & $\mathbf{A \mu F}$ & $\mu \mathbf{F}$ & $\mathbf{A \mu F}$ & $\mu \mathrm{F}$ \\
\hline \multirow{3}{*}{ Benzene } & 10 & 1.70 & 2.25 & 38.62 & 36.23 & 13.78 & 13.63 \\
\hline & 20 & 1.64 & 2.36 & 39.07 & 36.20 & 13.87 & 13.72 \\
\hline & 30 & 1.68 & 2.00 & 39.24 & 37.59 & 13.96 & 13.76 \\
\hline \multirow{3}{*}{ Toluene } & 10 & 1.43 & 1.58 & 41.05 & 40.17 & 14.28 & 14.16 \\
\hline & 20 & 1.70 & 1.43 & 40.48 & 40.94 & 14.37 & 14.24 \\
\hline & 30 & 1.59 & 1.64 & 41.12 & 40.64 & 14.16 & 14.36 \\
\hline \multirow{3}{*}{ Xylene } & 10 & 1.75 & 1.47 & 42.16 & 42.53 & 14.96 & 14.78 \\
\hline & 20 & 1.24 & 1.55 & 43.81 & 42.53 & 14.95 & 14.86 \\
\hline & 30 & 1.48 & 1.75 & 43.42 & 42.16 & 15.08 & 14.95 \\
\hline
\end{tabular}

Table 11. Values of enthalpy of absorption $\left(\Delta H_{s}\right)$, entropy of absorption $\left(\Delta S_{s}\right)$, and Gibbs free energy $\left(\Delta G_{s}\right)$ of Microfibre/LDPE Composites for $500 \mu m$. 
Table 12. Values of enthalpy of absorption $\left(\Delta H_{s}\right)$, entropy of absorption $\left(\Delta S_{s}\right)$, and Gibbs free energy $\left(\Delta G_{s}\right)$ of Microfibre/LDPE Composites for $600 \mu m$.

\begin{tabular}{|c|c|c|c|c|c|c|c|}
\hline \multirow{2}{*}{ Solvent } & \multirow[t]{2}{*}{ Filler Wt. \% } & \multicolumn{2}{|c|}{$\left(\Delta \mathrm{H}_{\mathrm{s}}\right), \times 10^{3} \mathrm{KJ} / \mathrm{mol}$} & \multicolumn{2}{|c|}{$\left(-\Delta \mathbf{S}_{\mathrm{s}}\right), \mathrm{J} / \mathrm{mol} / \mathrm{K}$} & \multicolumn{2}{|c|}{$\left(\Delta G_{\mathrm{s}}\right), x 10^{3} \mathrm{KJ} / \mathrm{mol}$} \\
\hline & & $\mathbf{A \mu F}$ & $\mu \mathrm{F}$ & $\mathbf{A \mu F}$ & $\mu \mathrm{F}$ & $\mathbf{A \mu F}$ & $\mu \mathbf{F}$ \\
\hline \multirow{3}{*}{ Benzene } & 10 & 1.48 & 2.57 & 38.82 & 34.81 & 13.93 & 13.47 \\
\hline & 20 & 1.22 & 2.78 & 39.94 & 34.49 & 13.72 & 13.57 \\
\hline & 30 & 1.57 & 2.00 & 39.13 & 37.16 & 13.82 & 13.63 \\
\hline \multirow{3}{*}{ Toluene } & 10 & 1.75 & 1.63 & 39.64 & 39.61 & 14.15 & 14.03 \\
\hline & 20 & 1.92 & 1.37 & 39.39 & 40.68 & 14.25 & 14.10 \\
\hline & 30 & 1.64 & 1.42 & 40.53 & 40.87 & 14.32 & 14.21 \\
\hline \multirow{3}{*}{ Xylene } & 10 & 1.34 & 1.13 & 42.92 & 42.99 & 14.78 & 14.59 \\
\hline & 20 & 1.36 & 1.30 & 43.01 & 42.72 & 14.82 & 14.28 \\
\hline & 30 & 1.43 & 1.34 & 43.13 & 42.92 & 14.93 & 14.78 \\
\hline
\end{tabular}

Gibbs Free Energy of Sorption $\left(\Delta G_{s}\right)$

The change in the Gibbs free energy of sorption $\left(\Delta G_{s}\right)$ for the three organic solvents in microfibre filled low density polyethylene composites are calculated using the expression;

$$
\Delta \mathrm{G}_{\mathrm{s}}=\Delta \mathrm{H}_{\mathrm{s}}-\mathrm{T} \Delta \mathrm{S}_{\mathrm{s}}
$$

where $\mathrm{T}$ is the absolute temperature. The values of $\Delta \mathrm{H}_{\mathrm{S}}$ and $\Delta \mathrm{S}_{\mathrm{S}}$ for the solvents calculated by equation (16) are used in equation (18), to get the values of $\Delta \mathrm{G}_{\mathrm{s}}$ which are presented also in Tables $10-12$. The calculated $\Delta \mathrm{G}_{\mathrm{s}}$ generally was found to show a direct relationship to the filler content, particle size, and alkali treatment. The positive values of free energy are an indication of the nonspontaneity of the solubility of the microfibre filled LDPE in the aromatic solvents calculated at $313 \mathrm{~K}$.

\subsection{Transport Kinetics}

The first order kinetic model has been used to evaluate the kinetics of diffusion of solvents through microfibre/LDPE composites. To apply this kinetic model, it is assumed that during the sorption of solvents, structural changes may occur in polymer chains, which may cause a rearrangement of the polymer segments that can dominate the kinetic behaviour. That is to say that the transport of liquids through a filled polymer is a rate-controlled kinetic process, which can be studied by first-order kinetic rate equation [7, 57].

$$
\frac{\mathrm{dC}}{\mathrm{dt}}=\mathrm{K}_{1}\left(\mathrm{C}_{\infty}-\mathrm{C}_{\mathrm{t}}\right)
$$

where, $\mathrm{K}_{1}$ is the first order rate constant, $\mathrm{C}_{\mathrm{t}}$ and $\mathrm{C}_{\infty}$ are the concentrations at time $\mathrm{t}$ and at equilibrium respectively. Equation (19) on integration gives;

$$
\log \left(\mathrm{C}_{\infty}-\mathrm{C}_{\mathrm{t}}\right)=\log \mathrm{C}_{\infty}-\frac{\mathrm{K}_{1} \mathrm{t}}{2.303}
$$

The plot of "Log $(\mathrm{C} \infty-\mathrm{Ct})$ " Vs " $\mathrm{t}$ " gives a straight line with slope equal to $-\mathrm{K}_{1} / 2.303$. Since the plot is a straight line we can say that sorption of aromatic solvents through these composites follows first order kinetics. From the slope of the plot, the values of rate constant at $80^{\circ} \mathrm{C}$ for all the solvents are determined and are presented in Table 13. The values were found to increase with the increase of fibre content, particle size and temperature but however, lower for modified composites. The trend is similar for other temperatures $\left(40\right.$ and $\left.60^{\circ} \mathrm{C}\right)$ studied. The values are highest for benzene, followed by toluene and then xylene. The rate constant values are a quantitative measure of the speed with which polymer composite absorbs the solvent. The increase of rate constant with temperature supports the fact that the

\begin{tabular}{|c|c|c|c|c|c|c|c|c|}
\hline \multirow[t]{3}{*}{ Solvent } & \multirow[t]{3}{*}{ Temp. ${ }^{\circ} \mathrm{C}$} & \multirow[t]{3}{*}{ Filler, wt. \% } & \multicolumn{6}{|c|}{$1^{\text {st }}$ Order Kinetic Rate Constants } \\
\hline & & & \multicolumn{2}{|c|}{$425 \mu \mathrm{m}$} & \multicolumn{2}{|c|}{$500 \mu \mathrm{m}$} & \multicolumn{2}{|c|}{$600 \mu \mathrm{m}$} \\
\hline & & & $\mathbf{A} \mu \mathbf{F}$ & $\mu \mathbf{F}$ & $\mathbf{A \mu F}$ & $\mu \mathbf{F}$ & $\mathbf{A \mu F}$ & $\mu \mathbf{F}$ \\
\hline \multirow{3}{*}{ Benzene } & & 10 & 4.34 & 4.48 & 4.48 & 4.74 & 4.70 & 4.97 \\
\hline & & 20 & 4.73 & 5.27 & 5.26 & 5.41 & 5.42 & 5.75 \\
\hline & & 30 & 4.98 & 5.42 & 5.34 & 5.58 & 5.54 & 5.92 \\
\hline \multirow[b]{2}{*}{ Toluene } & & 10 & 4.28 & 4.42 & 4.41 & 4.66 & 4.63 & 4.89 \\
\hline & 80 & 20 & 4.66 & 5.21 & 5.19 & 5.35 & 5.35 & 5.64 \\
\hline \multirow{3}{*}{ Xylene } & & 10 & 4.15 & 4.22 & 4.26 & 4.42 & 4.47 & 4.78 \\
\hline & & 20 & 4.47 & 4.99 & 5.02 & 5.19 & 5.26 & 5.53 \\
\hline & & 30 & 4.76 & 5.09 & 5.18 & 5.28 & 5.32 & 5.71 \\
\hline
\end{tabular}
rate of transport is favoured by increasing temperature.

Table 13. Values of Kinetic data $\left(k^{\prime} \times 10^{3} \mathrm{~min}^{-1}\right)$ of Microfibre/LDPE Composites at $80^{\circ} \mathrm{C}$.

\section{Conclusions}

The transport studies of three aromatic solvents (benzene, toluene, and xylene) through microfibre $(425,500$ and 600 $\mu \mathrm{m})$ filled LDPE have been investigated at three different temperatures $\left(40,60\right.$, and $\left.80^{\circ} \mathrm{C}\right)$. Also, the influence of filler content, penetrant size, filler particle size, fibre treatment and temperature on the diffusion process was analysed. The presence of micro filler creates a tortuous path for the transport of the solvent. As the microfiber content in the composites increases, the hindrance for the transport of solvent increases, and hence the uptake decreases. The swelling parameters, diffusion coefficient (D) and permeation coefficient $(\mathrm{P})$ values were found to decrease with microfibre content but with lower values for treated counterparts. The 
sorption coefficient values were found to exhibit a reverse order and increase with an increase in filler content. Solvent transport mechanism has been studied and in all cases mechanism of sorption follows Fickian trend. The swelling parameters and penetration rate have also been evaluated and were found to be dependent on the filler concentration and treatment. The calculated activation energy of permeation $\left(\mathrm{E}_{\mathrm{P}}\right)$, enthalpy of sorption $\left(\Delta \mathrm{H}_{\mathrm{s}}\right)$, and Gibbs free energy of sorption $\left(\Delta \mathrm{G}_{\mathrm{s}}\right)$ were all positive while the entropy of sorption $\left(\Delta \mathrm{S}_{\mathrm{S}}\right)$ and some of the activation energy $\left(\mathrm{E}_{\mathrm{D}}\right)$ were negative. The positive $\left(\Delta \mathrm{G}_{\mathrm{s}}\right)$ obtained in this study is an indication of nonspontaneity of the solubility of microfibre filled composites. It is found that first-order rate is temperature dependent and supports high diffusion rate at elevated temperature. The transport parameters presented in this study have not only provided additional characterization of the agro-waste microfibre filled low density polyethylene composites but gave an insight into the behaviour of microfibre/LDPE in an external liquid environment which is essential for their successful applications.

\section{References}

[1] Kutty, C. M., Sunilkumar, M., Sujith, A. and Jahfar, M. (2013), Molecular transport of chloromethanes through epdm/pvc systems. Acta Chim. Pharm. Indica, 3, 1, 10-16.

[2] Paul, D. (1984), Gas transport in homogeneous multicomponent polymers. Journal of membrane Science, 18, 75-86.

[3] Chiou, J. and Paul, D. R. (1986), Sorption and transport of $\mathrm{CO} 2$ in PVF2/PMMA blends. Journal of applied polymer science, 32, 1, 2897-2918.

[4] Roopa, S. and Guruprasad, K. (2003), Interaction of crosslinked ethylene-propylene-diene terpolymer blends with chlorinated organic penetrants. Journal of Applied Polymer Science, 88, 5, 1366-1375.

[5] Crank, J. and Park, G. S. (1968), Diffusion in polymers. Academic Press London.

[6] Odani, H., Uchikura, M., Ogino, Y. and Kurata, M. (1983), Diffusion and Solution of Methanol Vapor in Poly (2vinylpyridine)-block-Polyisoprene and Poly (2-vinylpyridine)block-Polystyrene. Journal of Membrane Science, 15, 2, 193-208.

[7] George, S. C., Thomas, S. and Ninan, K. (1996), Molecular transport of aromatic hydrocarbons through crosslinked styrene-butadiene rubber membranes. Polymer, 37, 26, 58395848 .

[8] Stephen, R., Varghese, S., Joseph, K., Oommen, Z. and Thomas, S. (2006), Diffusion and transport through nanocomposites of natural rubber (NR), carboxylated styrene butadiene rubber (XSBR) and their blends. Journal of membrane science, 282, 1, 162-170.

[9] Johnson, T. and Thomas, S. (1999), Natural rubber/epoxidised natural rubber-25 blends: morphology, transport phenomena and mechanical properties. Journal of materials science, 34 , $13,3221-3239$.

[10] Wang, J. and Wu, W. (2005), Swelling behaviors, tensile properties and thermodynamic studies of water sorption of 2 - hydroxyethyl methacrylate/epoxy methacrylate copolymeric hydrogels. European polymer journal, 41, 5, 1143-1151.

[11] Kumar, R. P. and Thomas, S. (2001), Interfacial adhesion in sisal fiber/SBR composites: an investigation by the restricted equilibrium swelling technique. Journal of adhesion science and technology, 15, 6, 633-652.

[12] Rezakazemi, M., Vatani, A. and Mohammadi, T. (2015), Synergistic interactions between POSS and fumed silica and their effect on the properties of crosslinked PDMS nanocomposite membranes. RSC Advances, 5, 100, 82460-82470.

[13] Farno, E., Rezakazemi, M., Mohammadi, T. and Kasiri, N. (2014), Ternary gas permeation through synthesized PDMS membranes: Experimental and CFD simulation based on a sorption-dependent system using neural network model. Polymer Engineering \& Science, 54, 1, 215-226.

[14] Cates, D. M. and White, H. J. (1956), Preparation and properties of fibres containing mixed polymers. I. Polyacrylonitrile - cellulose acetate fibres. Journal of Polymer Science, 20, 94, 155-180.

[15] Cates, D. M. and White, H. J. (1956), Preparation and properties of fibres containing mixed polymers. II. Polyacrylonitrile - cellulose fibres. Journal of Polymer Science, 20, 94, 181-195.

[16] Cates, D. M. and White, H. J. (1956), Preparation and properties of fibres containing mixed polymers. III. Polyacrylonitrile - silk fibres. Journal of Polymer Science, 21, 97, 125-138.

[17] Jacob, M., Varughese, K. and Thomas, S. (2005), Water sorption studies of hybrid biofiber-reinforced natural rubber biocomposites. Biomacromolecules, 6, 6, 2969-2979.

[18] Mathew, L., Joseph, K. and Joseph, R. (2006), Swelling behaviour of isora/natural rubber composites in oils used in automobiles. Bulletin of Materials Science, 29, 1, 91-99.

[19] Mathew, T. V. and Kuriakose, S. (2007), Molecular transport of aromatic hydrocarbons through lignin-filled natural rubber composites. Polymer Composites, 28, 1, 15-22.

[20] Gassan, J., Gutowski, V. S. and Bledzki, A. K. (2000), About the surface characteristics of natural fibres. Macromolecular Materials and Engineering, 283, 1, 132-139.

[21] Kwei, T. and Kunins, C. (1964), Polymer-filler interaction: Vapour sorption studies. Journal of Applied Polymer Science, $8,3,1483-1490$.

[22] George, S., Varughese, K. and Thomas, S. (2000), Molecular transport of aromatic solvents in isotactic polypropylene/acrylonitrile-co-butadiene rubber blends. Polymer, 41, 2, 579-594.

[23] Billmeyer, F. W. (1971), Textbook of polymer science.

[24] Ferreira, L., Falcao, A. and Gil, M. (2005), Modification of LDPE molecular structure by gamma irradiation for bioapplications. Nuclear Instruments and Methods in Physics Research Section B: Beam Interactions with Materials and Atoms, 236, 1, 513-520.

[25] Faisal, A. and Salmah, H. (2011), Mechanical and thermal properties of compatibilized waste office white paper-filled low-density polyethylene composites. Journal of Thermoplastic Composite Materials, 0892705711408164. 
[26] Diop, A., Mijiyawa, F., Koffi, D., Kokta, B. V. and Montplaisir, D. (2015), Study of lignin dispersion in lowdensity polyethylene. Journal of Thermoplastic Composite Materials, 28, 12, 1662-1674.

[27] Sarifuddin, N., Ismail, H. and Ahmad, Z. (2013), Studies of properties and characteristics of low-density polyethylene/thermoplastic sago starch-reinforced kenaf core fibre composites. Journal of Thermoplastic Composite Materials, 0892705713486125.

[28] Subramaniam, V., Menon, N. R., Sin, H. and May, C. Y. (2013), The development of a residual oil recovery system to increase the revenue of a palm oil mill. Journal of oil palm research, 25, 1, 116-122.

[29] Obasi, H. C., Ogbobe, O. and Igwe, I. O. (2009), Diffusion Characteristics of Toluene into Natural Rubber/Linear Low Density Polyethylene Blends. International Journal of Polymer Science, 2009, 1-6.

[30] Desai, A. B. and Wilkes, G. L. (1974), Solvent - induced crystallisation of polyethylene terephthalate. Wiley Online Library, City.

[31] Igwe, I. O. and Ezeani, O. E. (2012), Studies on the Transport of Aromatic Solvents through Filled Natural Rubber. International Journal of Polymer Science, 2012, 1-11.

[32] Sareena, C., Ramesan, M. T. and Purushothaman, E. (2012), Transport studies of peanut shell powder reinforced natural rubber composites in aromatic solvents. Polymer Composites, $33,10,1678-1692$.

[33] Joseph, S., Thomas, S., Joseph, K., Cvelbar, U., Panja, P. and Ceh, M. (2012), Molecular transport of aromatic solvents through oil palm microfiber filled natural rubber composites: the role of fibre content and interface adhesion on transport. Journal of Adhesion Science and Technology, 26, 1-3, 271-288.

[34] Bledzki, A. and Gassan, J. (1999), Composites reinforced with cellulose based fibres. Progress in Polymer Science, 24, 54.

[35] Mylsamy, K. and Rajendran, I. (2011), The mechanical properties, deformation and thermomechanical properties of alkali treated and untreated Agave continuous fibre reinforced epoxy composites. Materials \& Design, 32, 5, 3076-3084.

[36] Uragami, T., Morikawa, T. and Okuno, H. (1989), Characteristics of permeation and separation of aqueous alcohol solutions through hydrophobic polymer membranes. Polymer, 30, 6, 1117-1122.

[37] Okuno, H., Nishimoto, H., Miyata, T. and Uragami, T. (1993), Behaviour of permeation and separation for aqueous organic acid solutions through poly (vinyl chloride) and poly [(vinyl chloride) ${ }^{-} \mathrm{co}^{-}$(vinyl acetate)] membranes. Die Makromolekulare Chemie, 194, 3, 927-939.

[38] Padhi, S., ACHARY, P. G. R. and NAYAK, N. C. (2015), Molecular transport behaviour of organic solvents through halloysite nanotubes filled ethylene-vinyl acetate copolymer. Bulletin of Materials Science, 38, 4, 925-933.

[39] Sareena, C., Sreejith, M., Ramesan, M. and Purushothaman, E. (2015), Transport properties of coconut shell powder (CSP)-reinforced natural rubber composites in aromatic solvents. Polymer Bulletin, 72, 7, 1683-1702.

[40] George, S. C., Groeninckx, G., Ninan, K. and Thomas, S. (2000), Molecular transport of aromatic hydrocarbons through nylon - 6/ethylene propylene rubber blends: Relationship between phase morphology and transport characteristics. Journal of Polymer Science Part B: Polymer Physics, 38, 16, 2136-2153.

[41] Stephen, R., Joseph, K., Oommen, Z. and Thomas, S. (2007), Molecular transport of aromatic solvents through microcomposites of natural rubber (NR), carboxylated styrene butadiene rubber (XSBR) and their blends. Composites science and technology, 67, 6, 1187-1194.

[42] Crank, J. (1975), The Mathematics of Diffusion: 2d Ed. Clarendon Press.

[43] Peppas, N. and Ritger, P. L. (1987), A simple equation for description of solute release. I. Fickian and non-Fickian release from non-swellable devices in the form of slabs, spheres, cylinders or discs. J. Controlled Release, 5, 23-36.

[44] Etters, J. N. (1980), Diffusion Equations Made Easy. Textile Chemist \& Colorist, 12, 6 .

[45] Mullarney, M. P., Seery, T. A. and Weiss, R. (2006), Drug diffusion in hydrophobically modified $\mathrm{N}$, N-dimethyl acrylamide hydrogels. Polymer, 47, 11, 3845-3855.

[46] Johnson, T. and Thomas, S. (2000), Effect of epoxidation on the transport behaviour and mechanical properties of natural rubber. Polymer, 41, 20, 7511-7522.

[47] Unnikrishnan, G., Thomas, S. and Varghese, S. (1996), Sorption and diffusion of aromatic hydrocarbons through filled natural rubber. Polymer, 37, 13, 2687-2693.

[48] Michaels, A. S., Vieth, W., Hoffman, A. S. and Alcalay, H. A. (1969), Structure-property relationships for liquid transport in modified polypropylene membranes. Journal of Applied Polymer Science, 13, 4, 577-598.

[49] Visakh, P., Thomas, S., Oksman, K. and Mathew, A. P. (2012), Cellulose nanofibres and cellulose nanowhiskers based natural rubber composites: Diffusion, sorption, and permeation of aromatic organic solvents. Journal of Applied Polymer Science, 124, 2, 1614-1623.

[50] Aithal, U., Aminabhavi, T. and Cassidy, P. (1989), Barrier polymer and structures. City.

[51] Lucht, L. M. and Peppas, N. A. (1987), Transport of penetrants in the macromolecular structure of coals. V. Anomalous transport in pretreated coal particles. Journal of applied polymer science, 33, 5, 1557-1566.

[52] Wang, J., Wu, W. and Lin, Z. (2008), Kinetics and thermodynamics of the water sorption of 2 - hydroxyethyl methacrylate/styrene copolymer hydrogels. Journal of applied polymer science, 109, 5, 3018-3023.

[53] Bajpai, A., Bajpai, J. and Shukla, S. (2002), Water sorption through a semi-interpenetrating polymer network (IPN) with hydrophilic and hydrophobic chains. Reactive and Functional Polymers, 50, 1, 9-21.

[54] Kumnuantip, C. and Sombatsompop, N. (2003), Dynamic mechanical properties and swelling behaviour of NR/reclaimed rubber blends. Materials Letters, 57, 21, 3167-3174.

[55] Manjula, K. (2010), Sorption and Diffusion of Substituted Aromatic Organic Penetrants into Carboxylic Acid-Based Chain Extended Polyurethane Membranes. Journal of Chemical \& Engineering Data, 55, 6, 2271-2278. 
[56] Harogoppad, S. and Aminabhavi, T. (1991), Diffusion and sorption of organic liquids through polymer membranes. II. Neoprene, SBR, EPDM, NBR, and natural rubber versus $\mathrm{n}$ alkanes. Journal of applied polymer science, 42, 8, 2329-2336.
[57] Harogoppad, S. B., Aminabhavi, T. M. and Balundgi, R. H. (1991), Sorption and transport of aqueous salt solution in polyurethane membrane at 25,44 , and $60^{\circ} \mathrm{C}$. Journal of applied polymer science, 42, 5, 1297-1306. 